\title{
Non-linear Evolution of Double Tearing Modes in Tokamaks
}

\author{
E. Fredrickson, M. Bell, R. V. Budny, E. Synakowski
}

The $\Delta^{\prime}$ formalism with neoclassical modifications has proven to be a useful tool in the study of tearing modes in high $\beta$, collisionless plasmas. In this paper the formalism developed for the inclusion of neoclassical effects on tearing modes in monotonic qprofile plasmas is extended to plasmas with hollow current profiles and double rational surfaces. First, the classical formalism of tearing modes in the Rutherford regime in low beta plasmas is extended to q profiles with two rational surfaces. Then it is shown that this formalism is readily extended to include neoclassical effects.

\section{Introduction}

Tearing modes were early recognized as an important instability in tokamak plasmas[1,2]. The term "tearing mode" refers to an instability in which the resistivity of the plasma allows the magnetic field topology, which would be "frozen" in an ideal plasma, to relax to a more energetically favorable state. The process of relaxation can directly result in the transport of heat and particles in events such as "sawteeth" or disruptions[3]. Alternatively, the tearing modes can change the magnetic topology from one with simple nested flux surfaces to one with "magnetic islands" which have been shown to reduce the confinement of thermal energy[4]. Thus, avoidance of tearing modes is desirable for maximizing plasma performance.

A method of dealing simply with the boundary layer physics inherent in tearing mode theory has been developed in the so-called $\Delta^{\prime}$-formalism[5]. It has been shown that a full solution of the resistive MHD equations is not necessary to determine the stability of a given current profile to tearing modes. In this approach the "external" (i.e., outside the tearing boundary layer region) solutions are found through integration of a second order partial differential equation (PDE) in the region between the plasma magnetic axis and the rational surface (the boundary layer) and in the region from the rational surface to the plasma boundary. The solution, denoted by $\psi$, is called the perturbed helical flux function. The boundary conditions are that the solution be zero on axis, that it match the plasma edge boundary condition and that the solution matches across the boundary layer 
at the rational surface. The discontinuity across the boundary layer in the minor radial derivative of the solution represents the drive or damping on the tearing mode imposed by the external solution. This normalized discontinuity in the derivative, $\Delta^{\prime}$, is $\Delta^{\prime}=\left(\partial \psi^{\prime}\right.$ $\left./ \partial \mathrm{r}-\partial \psi^{+} / \partial \mathrm{r}\right) /\left.\psi\right|_{\mathrm{r}=\mathrm{r}_{\mathrm{s}}}$. For finite size islands, the discontinuity is taken between the inner and outer island edges with the perturbed flux, $\psi=$ constant across the island. This results in a $\Delta^{\prime}(\mathrm{w})$ which generally decreases as the island width $\mathrm{w}$ grows. Three boundary conditions may be used for the edge: a conducting wall at some radius, a vacuum boundary condition or an actively imposed boundary condition

The change in magnetic topology occurs in the boundary layer. The physics governing that topology change also sets the growth rate for the magnetic islands. Rutherford derived a simplified equation[6] governing the growth of islands larger than the boundary layer width in terms of $\Delta^{\prime}(\mathrm{w})$. For the parameters of discharges considered here the boundary layer width is small, much less than $1 \%$ of the plasma minor radius. Rutherford's equation predicts a growth rate proportional to $\Delta^{\prime}(\mathrm{w})$ :

$$
\mathrm{dw} / \mathrm{dt}=1.22 \eta / \mu \Delta^{\prime}(\mathrm{w}) \quad \text { Eq. } 1
$$

where $\eta$ is the plasma resistivity and $\mu$ is the magnetic permeability.

With the discovery in TFTR [7] of ubiquitous $\mathrm{m}>2$ modes (e.g., $\mathrm{m} / \mathrm{n}=3 / 2,4 / 3$, where $\mathrm{m}$ and $\mathrm{n}$ are the poloidal and toroidal mode numbers, respectively) in high beta, high temperature plasmas, it was realized that this simple resistive model was inadequate to describe tearing mode stability in high beta plasmas. For normal tokamak current profiles the $\mathrm{m} / \mathrm{n}=2 / 1$ mode is generally marginally unstable, but higher $\mathrm{m}$ modes are predicted to be strongly stable with $\Delta^{\prime}(0) \approx-2 \mathrm{~m} / \mathrm{r}_{\mathrm{s}}$. Thus, modifications to the simple resistive theory were necessary to account for the presence of the higher $\mathrm{n}$ islands.

It was pointed out by $\mathrm{Qu}$ and Callen [8] that the presence of islands could locally affect the bootstrap current, which was substantial in these plasmas, thereby influencing the non-linear mode stability. It had been predicted[8,9] and then confirmed experimentally[10] that for monotonic $\mathrm{q}$ profiles $(\partial \mathrm{q} / \partial \mathrm{r}>0$ everywhere) the evolution of 
the island width in the presence of the bootstrap effect is approximately described by solving the following equation:

$$
\mathrm{dw} / \mathrm{dt}=1.22 \eta / \mu\left[\Delta^{\prime}(\mathrm{w})+\Delta^{\prime}{ }_{\mathrm{nc}}\right] \quad \text { Eq. } 2
$$

In this expression the additional neoclassical term, $\Delta^{\prime}{ }_{\mathrm{nc}}$ is calculated assuming that the presence of the island flattens the temperature and density gradients across the island, thereby reducing the bootstrap current drive. This effectively drives a negative current at the island ' $\mathrm{O}$ ' point, which increases the island growth. The growth saturates when $\Delta^{\prime}(\mathrm{w})$ $+\Delta_{\mathrm{nc}}^{\prime}=0$.

The form of $\Delta^{\prime}{ }_{\text {nc }}$ may be heuristically derived as follows. With the assumption that the bootstrap current density is near zero in the island ' $\mathrm{O}$ ' point and unaffected at the ' $\mathrm{X}$ ' point, the amplitude of the effective perturbed current density is approximately $\mathrm{J}_{\mathrm{bs}} / 2$. This current can be related to a discontinuity in $\psi$ as:

$$
\left(\psi_{-}^{\prime}-\psi_{+}{ }^{\prime}\right) /\left.\mathrm{w}\right|_{\mathrm{r}=\mathrm{r}_{\mathrm{s}}}=[2 \pi / 5] \mathrm{J}_{\mathrm{bs}} / 2 \quad \text { Eq. } 3
$$

where $\mathrm{J}_{\mathrm{bs}}$ is in $\mathrm{A} / \mathrm{cm}^{2}$ and $\psi$ has units of G-cm. This can be written in the form of a $\Delta^{\prime}$ by relating $\psi$ to the island width. For small islands, the width can be found by making a parabolic approximation to $\psi_{0}$ in the region of the rational surface[5], where $\psi_{0}$ is the equilibrium helical flux function defined as:

$$
\psi_{0}(\mathrm{r})=\mathrm{B}_{0} / \mathrm{R}_{0} \int_{0}^{\mathrm{r}}(1 / \mathrm{q}(\mathrm{r})-\mathrm{n} / \mathrm{m}) \mathrm{r} d \mathrm{r} \quad \text { Eq. } 4
$$

This leads to the following equation relating island width to perturbed $\psi$ :

$$
\mathrm{w}^{2}=16\left(\psi / \psi_{\mathrm{o}}^{\prime \prime}\right)=\left[16 \mathrm{r}_{\mathrm{s}} /\left(\mathrm{s} \mathrm{B}_{\theta}\right)\right] \psi
$$

and then the destabilizing effect of the modulated bootstrap current can be introduced into the Rutherford island evolution equation as: 


$$
\Delta_{\mathrm{nc}}^{\prime}=\left(\psi_{-}^{\prime}-\psi_{+}^{\prime}\right) / \psi=16 \mathrm{k}_{1} \mathrm{~J}_{\mathrm{bs}} /(\mathrm{s} \mathrm{w}<\mathrm{J}>) \quad \text { Eq. } 6
$$

where $\mathrm{w}$ is the island width, $\mathrm{s}\left(\equiv \mathrm{r} \mathrm{q}^{\prime} / \mathrm{q}\right)$ is the magnetic shear at $\mathrm{r}=\mathrm{r}_{\mathrm{s}}, \mathrm{r}_{\mathrm{s}}$ is the radius of the mode rational surface, and $B_{\theta}$ is written in terms of $\langle J\rangle$, the average current density for the region $0<\mathrm{r}<\mathrm{r}_{\mathrm{s}}$. The derivation is not exact and a coefficient, $\mathrm{k}_{1}$, has been introduced. The coefficient will be adjusted to fit the data.

In neoclassical theory the bootstrap current, $\mathrm{J}_{\mathrm{bs}}$, has contributions from radial gradients in electron and ion temperature and density. In previous work, for simplicity, the bootstrap current is assumed to be proportional to the radial gradient of poloidal beta, $\beta_{\text {pol }}^{\prime}$ and a simple expression for $\Delta_{\text {nc }}^{\prime}$ results:

$$
\Delta_{\mathrm{nc}}^{\prime} \propto \mathrm{k} \varepsilon^{1 / 2} \beta_{\mathrm{pol}} \mathrm{r}_{\mathrm{s}} / \mathrm{s} \mathrm{L}_{\mathrm{p}} \quad \text { Eq. } 7
$$

where $\varepsilon=r_{s} / R$ is the inverse aspect ratio, and $L_{P}$ is the pressure gradient scale length. Previous papers [10-12] have chosen values in the range from 1.7-7 for the coefficient $\mathrm{k}$ to empirically fit experimental data. However, the evolution of the density gradient, and electron and ion temperature gradient terms need not be the same as the evolution of the total $\beta_{\text {pol }}$. In this work the bootstrap current, as calculated with the TRANSP code[13,14] for the measured and inferred gradients in actual plasmas, is used to calculate $\Delta_{\text {nc }}^{\prime}$.

In the limit of small island size, the neoclassical term becomes large, thereby implying instability for many tearing modes. However, in experiments, only some high beta plasmas had tearing modes, and typically only one or two modes were unstable in a given plasma. These experimental results could still be consistent with the theory if there was some threshold for instability of the tearing modes, i.e., that is that the plasmas without the tearing modes were in a metastable state.

Such a threshold is actually implicit in the model described above. For very small islands, the parallel connection lengths become long and parallel heat and particle transport will not be as effective in reducing the pressure gradient across the island ' $\mathrm{O}$ ' point. Thus, the effect of the island on the bootstrap current will no longer be linear in 
island size. To approximate this effect, the simple $1 / \mathrm{w}$ in the expression for $\Delta^{\prime}{ }_{\mathrm{nc}}$ is replaced with:

$$
1 / \mathrm{w}=>\mathrm{w} /\left(\mathrm{w}^{2}+\mathrm{w}_{\mathrm{d}}^{2}\right) \quad \text { Eq. } 8
$$

where $\mathrm{w}_{\mathrm{d}}$ is a parameter which measures the extent to which cross-field transport can support a parallel temperature or density gradient[ $[15,16]$. This model, which predicts that $\Delta_{\mathrm{nc}}^{\prime}=>0$ for small islands, only provides a threshold condition when $\Delta^{\prime}(0)<0$.

The contributions to the bootstrap current driven by the density, ion and electron temperature gradient will each have their own unique dependence on island size[17]. A more accurate formalism where the contributions to the bootstrap current from electron and ion density and temperature gradients are handled individually is probably necessary when studying threshold island physics. A detailed study of island threshold conditions is beyond the scope of this paper and will not be discussed in detail. For simplicity a single $\mathrm{w}_{\mathrm{d}}$ will be introduced to model the $\Delta_{\mathrm{nc}}^{\prime}$ at small island size. A more detailed study of the issue of threshold island size will be left to future papers.

Two other mechanisms have been identified which provide stabilizing terms at small island width, the so-called "Glasser-Greene-Johnson" [18] and the "polarization drift" terms[19-21]. The form of the Glasser-Greene-Johnson (GGJ) term used here is given in ref. 14, Eq. 51:

$$
\Delta_{\text {GGJ }}^{\prime}=-5.4\left(\beta_{\mathrm{p}} \varepsilon^{2} \mathrm{~L}_{\mathrm{q}}^{2}\right) /\left(\mathrm{rw} \mathrm{L}_{\mathrm{P}}\right)\left(1-\mathrm{q}^{2}\right) / \mathrm{q}^{2} .
$$

The $\Delta_{\text {GGJ }}^{\prime}$ term results from the average good curvature in a tokamak plasma. The simplified form for the polarization drift term commonly used is:

$$
\Delta_{\text {pol }}^{\prime}=-\left(\rho_{\theta i}^{2} \beta_{\mathrm{p}} \mathrm{g}\right) / \mathrm{w}^{3}\left(\mathrm{~L}_{\mathrm{q}} / \mathrm{L}_{\mathrm{p}}\right)^{2} . \quad \text { Eq. } 10
$$

The parameters $\mathrm{L}_{\mathrm{q}}$ and $\mathrm{L}_{\mathrm{P}}$ are the $\mathrm{q}$ and pressure gradient scale lengths, respectively. The ion poloidal gyroradius is $\rho_{\theta \mathrm{i}}$, the ion collision frequency is $v_{\mathrm{i}}$ and $\varepsilon$ is the local aspect ratio. The parameter $g$ approaches unity for $v_{\mathrm{i}} / \omega_{*_{\mathrm{e}}}<<1$ and $\varepsilon^{3 / 2}$ in the other extreme. 
Both of these terms become large and negative for small island size, but rapidly become small as the island size increases. Thus, introducing either of these terms into the island evolution equation will introduce a threshold condition on island width for instability. Islands below a critical size will be damped, even for some level of intrinsic instability $\Delta^{\prime}(0)>0$.

\section{Generalization of neoclassical $\Delta^{\prime}$ formalism to double tearing modes}

This paper will focus on the non-linear growth of finite sized double tearing modes. The linear stability of double tearing modes has been previously studied[22,23], as has non-linear stability without neoclassical effects[24,25]. The formalism developed in the previous section to describe the non-linear evolution of tearing modes in plasmas with monotonic q profiles will be generalized for two islands in reversed shear plasmas, i.e., with hollow plasma current profiles. The threshold island size will be discussed briefly.

When two identical rational surfaces are present in the plasma column, there are two boundary layers across which the external solutions must be matched. The external regions consist of Region I: $0<r<r_{1}$, Region II: $r_{1}<r<r_{2}$ and Region III: $r_{2}<r<r_{\text {wall }}$ where $r_{1}$ and $r_{2}$ are the inner and outer rational surfaces, respectively. The basis functions from which the radial eigenfunction is constructed are found by integration of the following equation in these three regions.

$$
\left[\partial^{2} / \partial \mathrm{r}^{2}+1 / \mathrm{r} \partial / \partial \mathrm{r}-\mathrm{m}^{2} / \mathrm{r}^{2}-\left(\partial \mathrm{J}_{0} / \partial \mathrm{r}\right) /\left(\partial \psi_{0} / \partial \mathrm{r}\right)\right] \psi_{\mathrm{m}, \mathrm{n}}=0
$$

$\psi_{\mathrm{m}, \mathrm{n}}$ is the perturbed helical flux function, $\mathrm{J}_{0}$ is the plasma current and $\psi_{0}$ was defined previously.

This formulation is a quasi-cylindrical model in that the $\mathrm{J}_{0}(\mathrm{r})$ and $\mathrm{q}(\mathrm{r})$ are taken from a toroidal equilibrium code (VMEC in TRANSP) so that $\mathrm{J}_{0}(\mathrm{r})$ and $\mathrm{q}(\mathrm{r})$ are not related by the simple cylindrical expression. This approach gets the rational surfaces in the right locations and keeps the $\mathrm{J}_{0}(\mathrm{r})$ and the $\mathrm{J}_{0}^{\prime}(\mathrm{r})$ reasonable.

In this paper we will restrict consideration to modes with finite island size, and the integration will be done to the edges of the islands. The $\psi$ is assumed constant across the 
island so the normalized discontinuity in the derivative is $\Delta^{\prime}\left[\equiv\left(\partial \psi / \partial \mathrm{r}-\partial \psi^{+} / \partial \mathrm{r}\right) / \psi\right]$ where the $+/$ - now refer to the outer and inner edges of the islands, respectively.

As the perturbed helical flux function is a solution to a second order PDE., there are two independent solutions for each region. For a single rational surface there would be two regions and the three boundary conditions $\left(\psi(0)=0, \psi^{+}\left(\mathrm{r}_{\mathrm{s}}\right)=\psi^{-}\left(\mathrm{r}_{\mathrm{s}}\right), \psi\left(\mathrm{r}_{\text {wall }}\right)=\right.$ edge boundary condition) constrain the solution to a unique $\Delta^{\prime}$. For the case with two rational surfaces, the four boundary conditions $\left(\psi(0)=0, \psi^{+}\left(\mathrm{r}_{\mathrm{s} 1}\right)=\psi\left(\mathrm{r}_{\mathrm{s} 1}\right), \psi^{+}\left(\mathrm{r}_{\mathrm{s} 2}\right)=\psi\left(\mathrm{r}_{\mathrm{s} 2}\right), \psi\left(\mathrm{r}_{\mathrm{wall}}\right)\right.$ $=$ edge boundary condition) are insufficient to uniquely define a $\Delta^{\prime}$ for each of the rational surfaces. For a unique solution, it is necessary to introduce a third parameter, the ratio of $\psi\left(\mathrm{r}_{1}\right)$ to $\psi\left(\mathrm{r}_{2}\right)$, or expressed differently, the ratio of the inner to outer island width.

The ratio of the island widths can be treated as an adjustable parameter and a pair of basis functions can be defined from which the solution, $\psi$, can be constructed. A unique definition of this pair of basis functions can be constructed for which the width of the inner island depends only on the amplitude of the inner basis function, $\psi_{1}\left(\mathrm{r}_{1}\right)$ and the width of the outer island depends only on the amplitude of the outer basis function, $\psi_{2}\left(\mathrm{r}_{2}\right)$. An example of this unique choice of basis functions for TFTR shot 92661 at 2.29 $\mathrm{s}$ is shown in Fig. 1. Any linear combination of these basis functions will satisfy the original P.D.E. and other linear combinations of these basis functions can be used to create a new pair of basis functions. However, as stated above, this particular choice of basis functions simplifies the calculation of the island width evolution as the width of the inner (outer) island depends only on the amplitude of $\psi_{1}\left(\psi_{2}\right)$. As the islands grow, the basis functions must be modified (slightly) to match the amplitude from the inner edge to the outer edge of the island and to keep $\psi_{2}=0$ at the outer edge of the inner island and $\psi_{1}$ $=0$ at the inner edge of the outer island.

The numerical solution to these equations described below uses the approximate relation (Eq. 5) between $\psi$ and $\mathrm{w}$ for small islands. As the island size becomes large, asymmetry about the rational surface makes this expression less accurate. The code relates $\mathrm{w}$ and $\psi\left(\mathrm{r}_{\mathrm{s}}\right)$ numerically by finding $\mathrm{dr}^{-}$and $\mathrm{dr}^{+}$such that:

$$
\psi_{0}\left(r_{s}-d r^{-}\right)+d \psi_{1}=\psi_{0}\left(r_{s}+d r^{+}\right)+d \psi_{1}=\psi_{0}\left(r_{s}\right)-d \psi_{1} . \quad \text { Eq. } 12
$$


However, the approximation is quite good for island sizes up to $10-20 \%$ of the minor radius. This can be seen in Fig. 2 where the actual and approximate island widths are compared.

The basis functions can be treated as independent, but strongly coupled eigenmodes. The growth of each of the modes (islands) is controlled by the $\Delta_{1}^{\prime}$ and $\Delta_{2}^{\prime}$ which depend on the widths of the magnetic islands. The explicit formulas are:

$$
\begin{array}{lll}
\Delta_{1}^{\prime}=\left(\partial \psi_{1}{ }^{-} / \partial \mathrm{r}-\partial \psi_{1}{ }^{+} / \partial \mathrm{r}\right) / \psi_{1}+\left(\partial \psi_{2}{ }^{+} / \partial \mathrm{r}\right) / \psi_{1} & \left.\right|_{\mathrm{r}=\mathrm{r}_{1}} & \text { Eq. 13a } \\
\Delta_{2}^{\prime}=\left(\partial \psi_{2}{ }^{-} / \partial \mathrm{r}-\partial \psi_{2}{ }^{+} / \partial \mathrm{r}\right) / \psi_{2}-\left(\partial \psi_{1}{ }^{-} / \partial \mathrm{r}\right) / \psi_{2} & \left.\right|_{\mathrm{r}=\mathrm{r}_{2}} & \text { Eq. 13b }
\end{array}
$$

The superscripts (+/-) refer to the inner and outer edges of the islands. These equations have the interesting property that for $\psi_{1}<<\psi_{2}$ (and thus $\mathrm{w}_{1}<<\mathrm{w}_{2}$ ) $\Delta_{1}^{\prime}$ becomes large and positive. Similarly for $\psi_{2}<<\psi_{1}, \Delta_{2}^{\prime}$ becomes large and positive. This is illustrated in Fig. 3 where $\Delta_{1}^{\prime}$ and $\Delta_{2}^{\prime}$ are graphed vs. a parameter, $\alpha$, which describes the relative amplitudes of the basis functions, $\psi_{1}$ and $\psi_{2}$, i.e., $\psi=(1-\alpha) \psi_{1}+\alpha \psi_{2}$. In the Rutherford regime of island growth, the growth rate is proportional to the $\Delta^{\prime}$, thus there is a natural tendency for both islands to have finite size.

This particular relation between $\Delta_{1}^{\prime}$ and $\Delta_{2}^{\prime}$ means that as the islands reach the Rutherford regime (island width is greater than the boundary layer width), the structure of the eigenfunction will naturally change as the "growth rates" for the inner and outer island need no longer be the same for the same overall eigenmode structure. For this reason, it is more reasonable to treat the inner and outer islands as separate, coupled modes.

\section{Experimental Observations}

Plasmas with hollow current profiles and thus a region of shear reversal in the core have been considered as attractive candidates for magnetically confined fusion plasmas[26]. The hollow current profile allows good bootstrap current alignment, minimizing the current drive necessary for steady-state operation. Good ion 
confinement, approaching neoclassical, has been observed in such reversed shear plasmas[27] and plasmas with negative shear are theoretically predicted to be stable to many forms of MHD.

Such plasmas were extensively studied on TFTR. It was found that the low beta, $\beta_{\text {pol }}$ $<0.5$, start-up phase of these plasmas in which very hollow current profiles had $\mathrm{q}_{\text {min }}$ (the value of $q$ at the shear reversal surface) dropping through rational surfaces, often showed bursts of MHD activity. The bursts were often benign, but also could result in minor disruptions and impurity accumulation or, in extreme cases, major disruptions. It was found that such bursts of MHD activity could be avoided by programming, at the proper time, pauses in the current ramp, gas puffs or notches in the NBI power. It was presumed that cooling the edge or temporarily reducing the current ramp rate allowed the edge current density to relax. An example of the start up of a typical reversed shear target plasma with MHD bursts on TFTR is shown in Figure 4. In Fig. 4a are shown the evolution of the $\mathrm{q}_{\min }$ and $\mathrm{q}(\mathrm{a})$ from a similar plasma for which MSE data[28] on the current profile is available. In Fig. $4 \mathrm{~b}$ and $4 \mathrm{c}$ are shown qualitatively the presence of MHD activity as bursts of coherent oscillations on Mirnov coils (Fig. 4b) and in the local electron temperature near the $\mathrm{q}_{\text {min }}$ radius (Fig. 4c). In this example the magnetic fluctuations betray the presence of both single and double tearing modes[29]. Note that the bursts of MHD activity are loosely correlated with $\mathrm{q}_{\min }$ passing through rational surfaces.

The evidence for the presence of double tearing modes is found in the data from the ECE Grating Polychromator diagnostics. An example of this data is shown in Figs. 5 and 6. The contour plot in Fig. 5 shows the bursts of internal MHD activity corresponding to the bursts of magnetic fluctuation activity as detected with the Mirnov coil array. In Fig. 6a (reproduced from Fig. 11 i n Ref. 29) the profiles of the electron temperature through the 'O' point of the inner and outer islands are shown. For better perspective, the data is translated via a simple time-to-space reconstruction[30] to a two dimensional image in Figure $6 \mathrm{~b}$. Two flatspots at the inner and outer $\mathrm{q}=3$ rational surface locations are seen, as well as a third flatspot corresponding to the location of the $\mathrm{q}=4$ rational surface. From the width of the flat spots, or from the flux surface displacement in the region between the islands, the island width can be estimated. From these figures, particularly Fig. 6b, it 
can be seen that the islands are relatively small. This width will be compared to the numerical simulations discussed below.

The last burst of activity in Figure 4 lasts from about 2.1 to $2.35 \mathrm{~s}$ and appears to be associated with the disruption which terminated the discharge. Analysis of the Mirnov fluctuations shows that they are dominated by an $m=6, n=1$ mode during the initial growth period, from about $2.09 \mathrm{sec}$ to $2.13 \mathrm{sec}$, After 2.13 seconds the dominant mode changes to an $m=4, n=1$ mode, suggesting that this mode was triggered shortly before this time. The phase data from which this determination is made is shown in Figure 7.

A detailed analysis of the phenomenology of the disruption in this discharge is beyond the scope of this paper. However, it is worthwhile to note that the magnetic fluctuations have remained constant in amplitude for a period of about $80 \mathrm{~ms}$ prior to the disruption. As will be seen below, the widths of the islands show a similar behavior. Thus, while it is tempting to consider the tearing modes to be the proximate cause of the disruption, the experimental evidence provides only very weak support for that model. Rather, it seems likely that these disruptions resemble disruptions in normal shear plasmas in that the "precursor" MHD activity sets up conditions which trigger a more virulent mode.

With this startup sequence, approximately $40 \%$ of the target plasmas had the burst of MHD at $1.4-1.5 \mathrm{~s}$ and a much smaller fraction had the burst around $2 \mathrm{sec}$. The techniques mentioned earlier could be quite successful in avoiding the burst at 1.4-1.5 s, dropping the occurrence rate to around $10 \%$. There were no obvious differences in the measured current profile with or without the MHD. MSE data is not available for the shot with the $(2,1)$ double tearing discussed in this paper. A similar shot for which MSE data is available was used for the current profile in the following calculations. The similarity of the q profile between these two shots is suggested by the less than $3 \%$ variation in the $\beta_{\mathrm{pol}}$ and in the $\Lambda\left(\equiv \beta_{\mathrm{pol}}+1_{\mathrm{i}} / 2\right)$ from magnetics measurements. Further, signatures of Type II confinement transitions [31] which are associated with $\mathrm{q}_{\min }=$ rational number crossings, in this case $\mathrm{q}_{\min }=3$, are seen at about $1.85 \mathrm{~s}$ in both shots $(c . f$. Fig. 5). This, together with the simulations discussed below, suggests that the double tearing modes are not linearly unstable at the rational $\mathrm{q}_{\min }$ crossings, but that some trigger mechanism is necessary which then destabilizes the tearing mode. 


\section{Numerical Simulations}

A numerical code previously used extensively for tearing mode studies in normal shear plasmas has been adapted for hollow current profiles with two rational surfaces. As discussed above, the basis functions are calculated from TRANSP output files. As described above, the code finds the two basis functions, $\psi_{1}$ and $\psi_{2}$, by numerical integration of Eq. 11. From these, the $\Delta_{1}^{\prime}\left(\mathrm{w}_{1}, \mathrm{w}_{2}, \alpha\right)$ and $\Delta_{2}^{\prime}\left(\mathrm{w}_{1}, \mathrm{w}_{2}, \alpha\right)$ can be found. The parameter " $\alpha$ " describing the linear weighting of the two basis functions is found from the island widths using Eq. 1, or a numerical calculation for larger island width, to relate the island widths to the basis function amplitudes.

The growth of the islands can then be simulated by treating the basis functions as separate, but strongly coupled modes and numerically integrating the Rutherford equation in time to track the island width evolution.

$$
\begin{array}{ll}
\mathrm{dw}_{1} / \mathrm{dt}=\eta\left(\mathrm{r}_{1}\right) / \mu \Delta_{1}^{\prime}\left(\mathrm{w}_{1}, \mathrm{w}_{2}\right) & \text { Eq. } 14 \mathrm{a} \\
\mathrm{dw}_{2} / \mathrm{dt}=\eta\left(\mathrm{r}_{2}\right) / \mu \Delta_{2}^{\prime}\left(\mathrm{w}_{1}, \mathrm{w}_{2}\right) & \text { Eq. } 14 \mathrm{~b}
\end{array}
$$

In the time integration, the basis functions are recalculated for each TRANSP time step, i.e., roughly every $10 \mathrm{msec}$. Between each time step, the $\Delta^{\prime}$ s are recalculated as the island widths change, using the basis functions from the last TRANSP time point.

An example of a numerical solution to the problem described above is shown in Figure 8. This calculation was done using current profiles, pressure profiles and bootstrap current profiles as calculated by the TRANSP analysis code for a target plasma similar to the one shown in Fig. 6 (MSE measurements of the current profile evolution were not available on the plasma shot in which the $m=3, n=1$ mode was seen). The calculation was done for the $\mathrm{m}=3, \mathrm{n}=1$ mode, beginning before the $\mathrm{q}_{\min }$ dropped below three. This calculation was done without the neoclassical, Glasser-Greene-Johnson or polarization terms. As is commonly found, the mode in this case robustly becomes unstable when $\mathrm{q}_{\min }$ drops slightly below three. 
The inner and outer island widths from this purely resistive calculation are about half the measured island widths. The predicted onset time for the mode is also well before the experimentally observed mode onset time. While there is probably some variation in the q-profile time evolution between plasma shots, it is outside the experimental uncertainty that the variation would be this large, based on comparisons of such similar shots where MSE data was available, and, as mentioned above, the comparison of $\Lambda, \beta_{\mathrm{pol}}$ and the timing of the Type II transition signatures. These two observations suggest that including the neoclassical and/or GGJ terms is necessary to provide a threshold condition for island onset (to explain the delay in island growth) and to drive the saturated island to larger amplitude.

A simulation done including just the neoclassical term reasonably matches the size of the outer island. In these simulations (Fig. 9) the mode onset is triggered at $2.09 \mathrm{sec}$, consistent with the experimental mode onset time. As can be seen in Fig. 9 the mode growth rate is in reasonably good agreement with the experimental data. In both the experiment and the simulation, the mode saturates at a relatively small size; the outer island width is about $10 \%$ of the minor radius. As previously discussed, the derivation of the neoclassical term does not yield an exact value for the coefficient $\mathrm{k}$ which is adjusted to match the saturated width of the outer island; in Eq. $6 \mathrm{k}_{1}=2.0$ was necessary to match the island width. This is to be compared with $\mathrm{k}_{1}$ 's in the range of $0.5-0.8$ to match island widths in normal shear, high $\beta$ plasmas.

The addition of the neoclassical bootstrap current term is, again in this case, not sufficient to provide a threshold island size condition as the resistive $\Delta^{\prime}$ is positive. However, the saturated island size in this case can be strongly affected by the assumption of the form for the parallel electron heat transport. With the assumption of collisionless parallel heat transport (Eq. 14 in ref. 11$), \mathrm{w}_{\mathrm{d}}$ is approximately $7-8 \mathrm{~cm}(v s . \approx 2 \mathrm{~cm}$ in the collisional estimate). This means that $\mathrm{w}_{\mathrm{d}}$ plays an important role in the saturated island width. The multiplicative factor on the neoclassical term to match the saturated island size is $\mathrm{k} \approx 3$ if the collisionless estimate of $\mathrm{w}_{\mathrm{d}}$ of $\approx 7-8 \mathrm{~cm}$ is used.

In the simulation with neoclassical effects, the inner island is predicted to be much smaller than the outer island. This is expected since the neoclassical effects are stabilizing in regions of reversed shear. However, this predicition is not in agreement 
with the experimental observations where the inner island is roughly $60 \%$ as large as the outer island. It is interesting to note that the predicted inner island size is in good agreement with the measurement if the neoclassical term in the reversed shear region is turned off, although there is no justification for doing so.

Some or all of this discrepancy might be alleviated if the coupling of the $(3,1)$ and $(4,1)$ modes were considered. The approach described above for modeling the coupling of double tearing modes could be extended to coupling of tearing modes with disparate poloidal mode numbers with an appropriate model describing the poloidal coupling. If the coupling to the $(4,1)$ mode were destabilizing, which it should be, then the scale factor on the neoclassical term could be reduced on both the inner and outer $(3,1)$ islands. This would have the effect of increasing the size of the inner island. A simulation was done where the outer island was forced to the proper amplitude and the neoclassical term for the inner island was reduced to a 'typical' size by setting $\mathrm{k}_{1}=0.5$. In this case the peak size of the inner island was still too small with a width of about $3.5 \%$ of the minor radius.

The delay in mode onset, as well as some of the experimental data, is consistent with a model in which a "seed" island is necessary to overcome some threshold condition as in normal-shear neoclassical tearing mode studies. A low amplitude oscillation was visible on the ECE temperature measurements well before the fast mode growth started at $2.09 \mathrm{~s}$. This is visible in the experimental data presented in Figures 8 and 9 as the "measured island size". At these small amplitudes, it is not possible to tell from the ECE data whether an island is actually present, or whether the perturbation around the $q=3$ rational surfaces is more ideal in character. It is proposed that the oscillations seen near $q=3$ are driven by poloidal coupling from higher-m tearing modes nearer the plasma edge. These ideal perturbations will, on a resistive timescale, drive reconnection at the $\mathrm{q}=3$ surfaces, generating the seed islands needed to overcome the polarization and Glasser-GreeneJohnson stabilizing terms.

The island widths in the final simulations are in reasonable agreement, as well as the growth rate. However, the simulation predicts a poloidal field fluctuation amplitude of about 2 Gauss at the wall. Experimentally, the mode amplitude is about 18 Gauss, and the dominant poloidal mode number at the Mirnov coils is $m=4$, rather than the $m=3$ 
which is being simulated. The magnetic fluctuation measured at the vacuum vessel wall is more than likely dominated by the $m=4, n=1$ mode, visible as a flat spot in the electron temperature profile in Fig. 6. In this case, the 4/1 mode might, through toroidal coupling, provide the seed island for the 3/1 double tearing mode. An $m=4, n=1$ island with a width of about 7-8\%, consistent with the ECE data, would result in a magnetic fluctuation level of about 9 Gauss at the location of the Mirnov coils. The remaining 7 Gauss is likely attributable to the $m=5, n=1$ and $m=6, n=1$ islands.

\section{Summary}

In this paper a new formalism for the simulation of double tearing modes, including neoclassical effects, has been presented. Simulations based on this model have been compared to experimental data and reasonable agreement has been found. The model naturally suggests that, like neoclassical tearing modes, double tearing modes can also be metastable. That is, for very small island sizes the growth rates are negative, however, above some threshold island size, they become positive, i.e., the modes are unstable. This threshold island size may be the result of Glasser-Greene-Johnson or polarization current physics. It has also been shown that in finite beta, hollow current profiles, the neoclassical terms naturally stabilize the island in the negative shear region.

\section{Acknowledgments}

The authors are very grateful to Dr. G. Taylor for the use of the fast electron temperature data and Drs. F. Levinton and S. Batha for the use of the MSE data. One of the authors (E. D. F.) would like to acknowledge useful discussions with Drs. D. Monticello, R. White, J. Hastie and F. Nave. This work is supported under DoE Contract No DE-AC02-76CH03073. 


\section{Bibliography}

[1] S. V. Mirnov, I. G. Semenov, Sov. Journal of Atomic Energy 30, 22 (1971) or Sov. Phys. JETP 33, 1134 (1971).

[2] H. P. Furth, J. Killeen, M. N. Rosenbluth, Phys. Fluids 6, 459 (1963).

[3] B. B. Kadomtsev, Fiz Plazmy 1, 710 (1975) [Sov. J. Plasma Phys. 1, 389 (1975)]

[4] Z. Chang, E. D. Fredrickson, J. D. Callen, K. M. McGuire, M. G. Bel, R. B. Budny, C. E. Bush, D. S. Darrow, A. C. Janos, L. C. Johnson, H. K. Park, S. D. Scott, J. D. Strachan, E. J. Synakowski, G. Taylor, R. M. Wieland, M. C. Zarnstorff, S. J. Zweben, and the TFTR Team, Nucl. Fusion 34, 1309 (1994).

[5] R. B. White, D. A. Monticello, M. N. Rosenbluth, and B. V. Waddell,., Phys. Fluids 20, 800 (1977).

[6] P. H. Rutherford, Phys. Fluids 16, 1903, (1973).

[7] K.M. McGuire, et al., in Plasma Physics and Controlled Nuclear Fusion Research 1986 (Proc. 11 ${ }^{\text {th }}$ Int. Conf. Kyoto, 1986), Vol. I, IAEA, Vienna (1987) 421.

[8] W. X. Qu and J. D. Callen, University of Wisconsin Report No. UWPR-85-5, 1985 (unpublished).

[9] R. Carrera, R. D. Halzeltine, and M. Kotschenreuther, Phys. Fluids 29, 899 (1986).

[10] Z. Chang, J. D. Callen, E. D. Fredrickson, R. V. Budny, C. C. Hegna, K. M. McGuire, M. C. Zarnstorff, and the TFTR Group, Phys. Rev. Lett. 74, 4663 (1995).

[11] Z. Chang, E. D. Fredrickson, S. H. Batha, M. G. Bell, R. V. Budny, F. M. Levinton, K. M. McGuire, G. Taylor, M. C. Zarnstorff and the TFTR Group, Phys. of Plasmas 5, 1076 (1998).

[12] D. A. Gates, B. Lloyd, A. W. Morris, G. McArdle, M. R. O’Brien, M. Valovic, C. D. Warrick, H. R. WIlson, COMPASS-D Team, ECRH Team, Nucl. Fusion 37, 1593 (1997).

[13] R. V. Budny, Nucl. Fusion 34, 1247 (1994), and references therein. 
[14] W. Houlberg, K. Shang, S. Hirshman, and M. Zarnstorff, Phys. of Plasmas 4, 3230 (1997).

[15] R. Fitzpatrick, Phys. Plasmas 2, 825 (1995).

[16] T. A. Gianakon, C. C. Hegna, J. D. Callen, University of Wisconsin Report No. UW-CPTC 96-4, June 1996 (unpublished).

[17] N. N. Gorelenkov, R. V. Budny, Z. Chang, M. V. Gorelenkova, and L. E. Zakharov, Phys. Plasmas 3, 3379 (1996).

[18] A. H. Glasser, J. M. Greene, and J. L. Johnson, Phys. Fluids 18, 875 (1975).

[19] A. I. Smolyakov, A. Hirose, E. Lazzaro, G. B. Re, J. D. Callen, Phys. Plasmas 2, 1581 (1995).

[20] M. F. Zabiego and J. D. Callen, University of Wisconsin Report No. UW-CPTC 96-2, March 1996 (unpublished).

[21] H. R. Wilson, J. W. Conner, R. J. Hastie, and C. C. Hegna, Phys. of Plasmas 3, 248 (1996).

[22] P. L. Pritchett, Y. C. Lee, and J. F. Drake, Phys. Fluids 23, 1368 (1980).

[23] L. Ofman, Phys. Fluids B 4, 2751 (1992).

[24] R. B. White, D. A. Monticello, M. N. Rosenbluth, and B. V. Waddell, IAEA...

[25] Z. Chang, W. Park, E. D. Fredrickson, S. H. Batha, M. G. Bell, R. Bell, R. V. Budny, C. E. Bush, A. Janos, F. M. Levinton, K. M. McGuire, H. Park, S. A. Sabbagh, G. L. Schmidt, S. D. Scott, E. J. Synakowski, H. Takahashi, G. Taylor, and M. C. Zarnstorff, Phys. Rev. Lett. 77, 3553 (1996).

[26] C. Kessel, J. Manickam, G. Rewoldt, and W. M. Tang, Phys. Rev. Lett. 72, 1212 (1994).

[27] F. Levinton and M. Zarnstorff, Phys. Rev. Lett.

[28] F. Levinton, Rev. Sci. Instrum. 63, 5157 (1992).

[29] E.D. Fredrickson, S.A. Sabbagh, M.G. Bell, D. Mansfield, S. Batha, Z. Chang, F. Levinton, K.M. McGuire, M. Okabayashi, G. Taylor, H. Takahashi, M. Hughes, J. Manickam, M. Phillips, and L. Zakharov, Phys. Plasmas 4, 1589 (1997).

[30] Y. Nagayama, G. Taylor, E. D. Fredrickson, R. V. Budny, A. C. Janos, D. K. Mansfield, K. M. McGuire, and M. Yamada, Phys. of Plasmas 3, 2631 (1996). 
[31] R. E. Bell, S. H. Batha, M. Beer, C.E. Bush, Z. Chang, P.C. Efthimion, T.S. Hahm, G. Hammett, F. Levinton, B. LeBlanc, E. Mazzucato, D. Mikkelsen, H. Park, S. Paul, G. Rewoldt, G.L. Schmidt, S.D. Scott, E.J. Synakowski, G. Taylor, M.C. Zarnstorff and the TFTR Group, in Proceedings of the $23^{\text {rd }}$ European Physical Society Conf. on Plasma Physics and Controlled Fusion Research, (Proc. 23 ${ }^{\text {rd }}$ EPS Conf., Kiev, 24-28 June 1996), Vol. 20c, Part I, p 59 (1996). 


\section{Figures}

Figure 1 Basis functions for illustration.

Figure 2 Island width as estimated with the approximate formula compared to actual island width.

Figure $3 \Delta_{1,2}^{\prime}(\mathrm{w}, \alpha)$ for the example in Figures 1 and 2.

Figure 4 Time evolution of $\mathrm{q}_{\text {min }}$ and $\mathrm{q}(\mathrm{a})$ compared to, b) Mirnov coil trace and, c) local electron temperature near $\mathrm{q}_{\min }$ surface.

Figure 5 Contour plot of electron temperature showing presence of tearing modes.

Figure 6a Radial profiles of electron temperature in a restricted radial range about the at two extreme phases of the magnetic islands. The flat spots consistent with the presence of double tearing modes are indicated as well as a flat spot consistent with an $\mathrm{m}=4, \mathrm{n}=1$ island.

Figure $6 \mathrm{~b}$ Reconstruction from the data presented in Figure 6a of a 2-dimensional image showing contours of electron temperature every $500 \mathrm{eV}$. The two $3 / 1$ islands are indicated in the Figure.

Figure 7a Phase relationship analysis of last MHD burst at $2.125 \mathrm{~s}$ at a frequency of 1.47 $\mathrm{kHz}$. Best fit was for $\mathrm{m}=6, \mathrm{n}=1$ with $\Lambda=0.83, \mathrm{r}=0.84 \mathrm{~m}$.

Figure 7b Phase analysis of last MHD burst at $2.135 \mathrm{sec}$. Best fit was for $m=4, n=1$ with $\Lambda=0.83, \mathrm{r}=0.84 \mathrm{~m}$. 
Figure 8 Resistive simulation of double tearing mode evolution. The solid line is the calculated outer island width, dashed line is the calculated inner island width. The open squares are the measured outer island width and the solid circles are the measured inner island width.

Figure 9 Simulation of double tearing mode with neoclassical term but without the polarization and GGJ terms. The solid line is the calculated outer island width, dashed line is the calculated inner island width. The open squares are the measured outer island width and the solid circles are the measured inner island width.

Figure 10 Simulation of double tearing mode evolution with the outer island driven to the measured width and no neoclassical term for the inner island. The solid line is the calculated outer island width, dashed line is the calculated inner island width. The open squares are the measured outer island width and the solid circles are the measured inner island width. 


\section{Appendix A}

To verify that this approximate solution was sufficiently accurate, a more detailed calculation relating the island widths to the amplitudes of $\psi_{1}$ and $\psi_{2}$ was also done. For this calculation, the equations for $\Delta^{\prime}$ are:

$$
\begin{aligned}
& \Delta_{1}^{\prime}=\left(\partial \psi_{1}{ }^{-} / \partial \mathrm{r}\right) / \psi_{1}\left(\mathrm{r}_{\mathrm{s} 1}-\mathrm{dr}_{1}\right)-\left(\partial \psi_{1}{ }^{+} / \partial \mathrm{r}\right) / \psi_{1}\left(\mathrm{r}_{\mathrm{s} 1}+\mathrm{dr}_{1}\right)+\psi_{2}{ }^{+} /\left[\psi_{2}\left(\mathrm{r}_{\mathrm{s} 2}-\mathrm{dr}_{2}\right)-\psi_{2}\left(\mathrm{r}_{\mathrm{s} 1}+\mathrm{dr}_{1}\right)\right] \\
& \Delta_{2}^{\prime}=\left(\partial \psi_{2}{ }^{-} / \partial \mathrm{r}\right) / \psi_{2}\left(\mathrm{r}_{\mathrm{s} 2}-\mathrm{dr}_{2}\right)-\left(\partial \psi_{2}{ }^{+} / \partial \mathrm{r}\right) / \psi_{2}\left(\mathrm{r}_{\mathrm{s} 2}+\mathrm{dr}_{2}\right)-\psi_{1}{ }^{-} /\left[\psi_{1}\left(\mathrm{r}_{\mathrm{s} 1}-\mathrm{dr}_{1}\right)-\psi_{1}\left(\mathrm{r}_{\mathrm{s} 2}-\mathrm{dr}_{2}\right)\right]
\end{aligned}
$$

For each set of island widths, $\mathrm{w}_{1}$ and $\mathrm{w}_{2}$, it is necessary to redefine the basis functions as follows:

In the first and third regions:

$$
\begin{aligned}
& \psi_{1}^{-}=\mathrm{s}_{1} * \psi_{1}(\mathrm{r}) / \psi_{1}\left(\mathrm{r}_{1}-\delta \mathrm{r}_{1}\right) \\
& \chi_{1}{ }^{-}=\mathrm{s}_{1} * \chi_{1}(\mathrm{r}) / \psi_{1}\left(\mathrm{r}_{1}-\delta \mathrm{r}_{1}\right) \\
& \psi_{2}^{+}=\mathrm{s}_{2} * \psi_{2}(\mathrm{r}) / \psi_{2}\left(\mathrm{r}_{2}+\delta \mathrm{r}_{2}\right) \\
& \chi_{2}{ }^{+}=\mathrm{s}_{2} * \chi_{2}(\mathrm{r}) / \psi_{2}\left(\mathrm{r}_{2}+\delta \mathrm{r}_{2}\right)
\end{aligned}
$$

in the second region, define two parameters:

$$
\begin{aligned}
& \alpha=\psi_{1}{ }^{+}\left(r_{2}-\delta r_{2}\right) / \psi_{2}{ }^{-}\left(r_{2}-\delta r_{2}\right) \\
& \beta=\psi_{2}{ }^{-}\left(r_{1}+\delta r_{1}\right) / \psi_{1}{ }^{+}\left(r_{1}+\delta r_{1}\right)
\end{aligned}
$$

then the basis functions in the second region can be redefined as:

$$
\psi_{1}^{+}=\mathrm{s}_{1} *\left(\psi_{1}(\mathrm{r})-\alpha \psi_{2}(\mathrm{r})\right) /\left(\psi_{1}\left(\mathrm{r}_{1}+\delta \mathrm{r}_{1}\right)-\alpha \psi_{2}^{-}\left(\mathrm{r}_{1}+\delta \mathrm{r}_{1}\right)\right)
$$




$$
\chi_{1}^{+}=\mathrm{s}_{1} *\left(\chi_{1}(\mathrm{r})-\alpha \chi_{2}(\mathrm{r})\right) /\left(\psi_{1}\left(\mathrm{r}_{1}+\delta \mathrm{r}_{1}\right)-\alpha \psi_{2}{ }^{-}\left(\mathrm{r}_{1}+\delta \mathrm{r}_{1}\right)\right)
$$

and:

$$
\begin{aligned}
& \psi_{2}^{-}=\mathrm{s}_{2} *\left(\psi_{2}(\mathrm{r})-\beta \psi_{1}(\mathrm{r})\right) /\left(\psi_{2}\left(\mathrm{r}_{2}+\delta \mathrm{r}_{2}\right)-\beta \psi_{1}^{+}\left(\mathrm{r}_{2}-\delta \mathrm{r}_{2}\right)\right) \\
& \chi_{2}^{-}=\mathrm{s}_{2} *\left(\chi_{2}(\mathrm{r})-\beta \chi_{1}(\mathrm{r})\right) /\left(\psi_{2}\left(\mathrm{r}_{2}+\delta \mathrm{r}_{2}\right)-\beta \psi_{1}^{+}\left(\mathrm{r}_{2}-\delta \mathrm{r}_{2}\right)\right)
\end{aligned}
$$

The $\Delta$ 's are then:

$$
\Delta_{1}{ }^{\prime}=\left(\chi_{1}^{+}\left(\mathrm{r}_{1}+\delta \mathrm{r}_{1}\right)-\chi_{1}^{-}\left(\mathrm{r}_{1}-\delta \mathrm{r}_{1}\right)+\chi_{2}^{+}\left(\mathrm{r}_{1}+\delta \mathrm{r}_{1}\right)\right) / \psi_{1}\left(\mathrm{r}_{1}\right)
$$


Figure 1

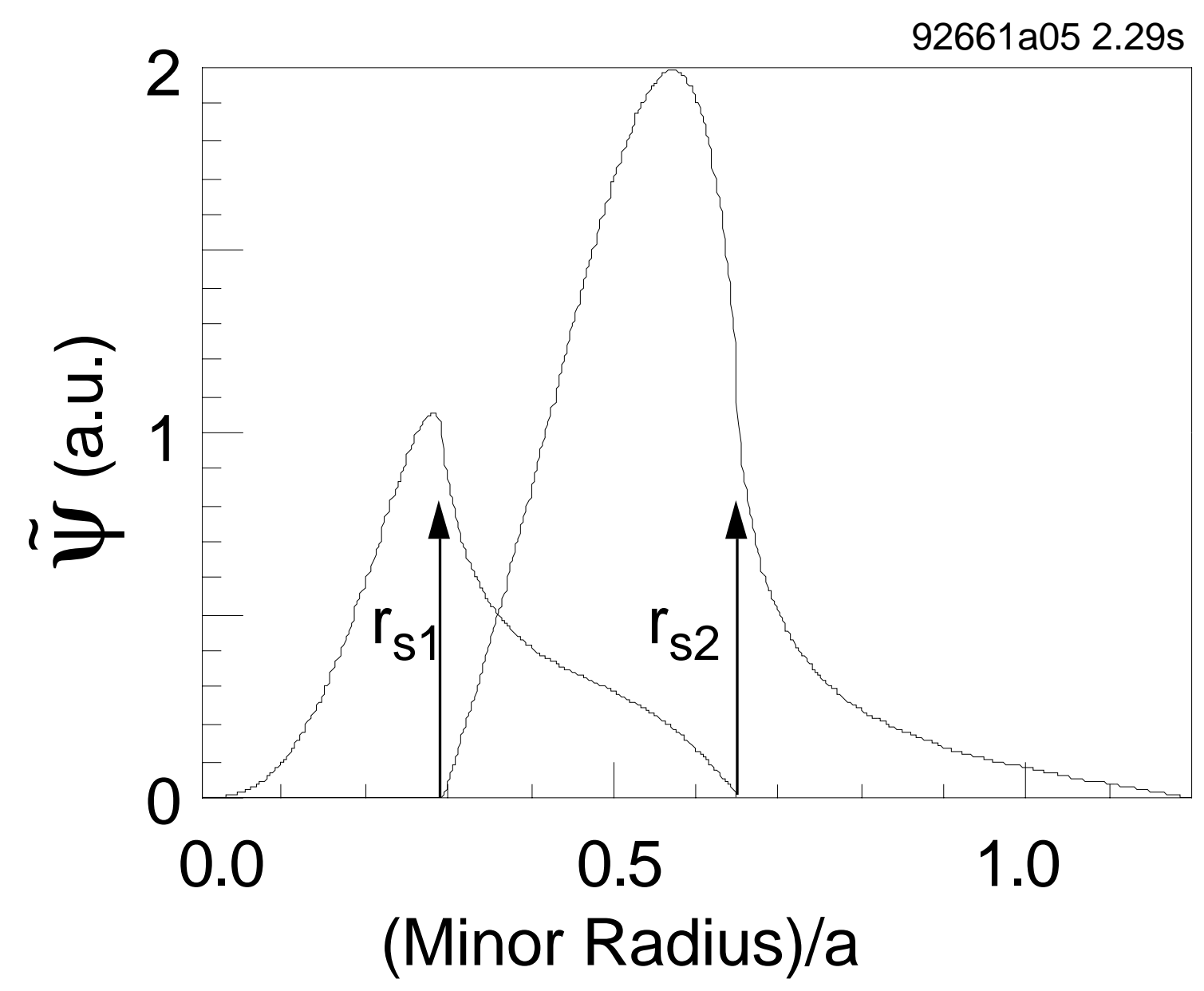


Figure 2

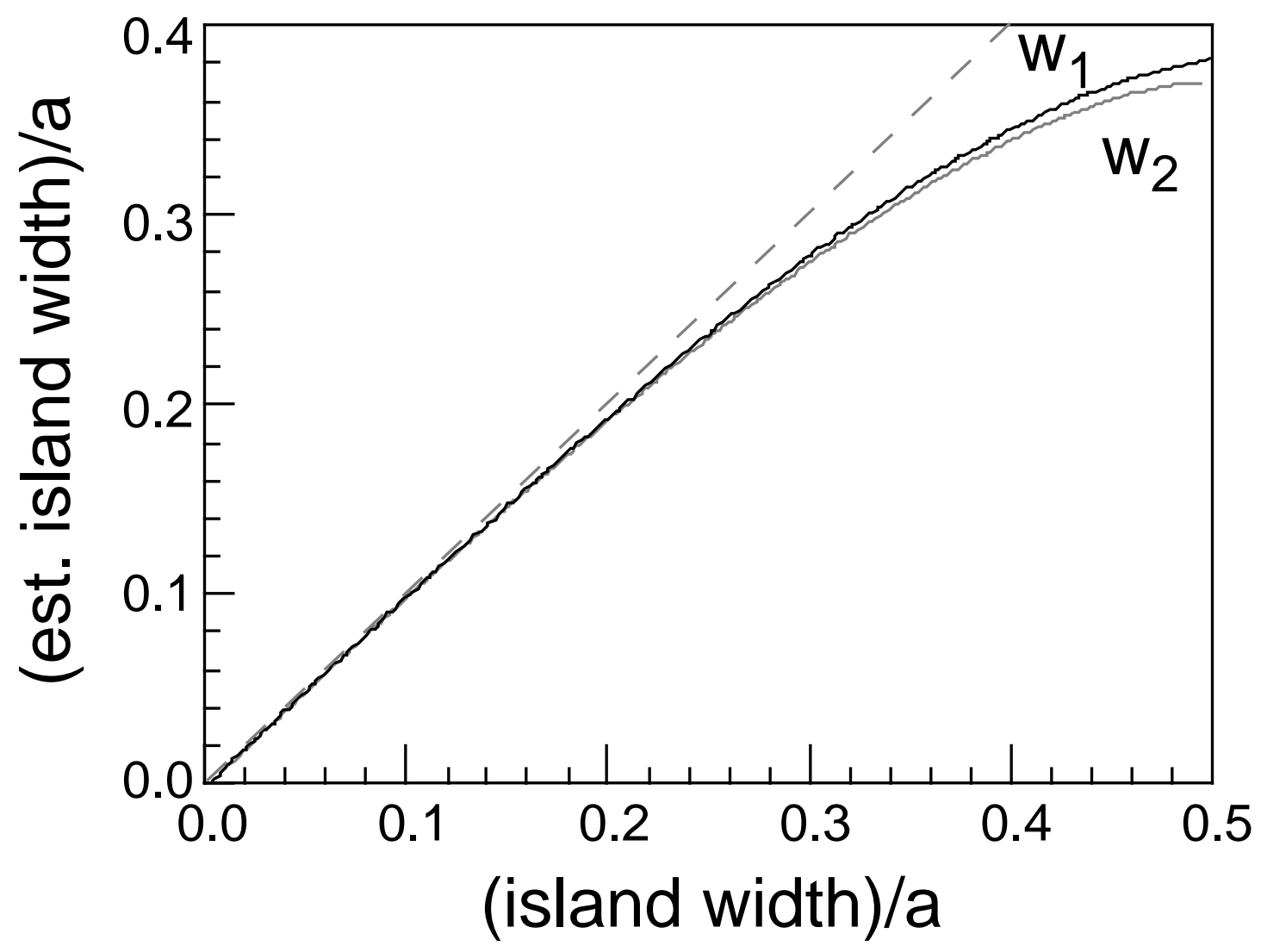


Figure 3

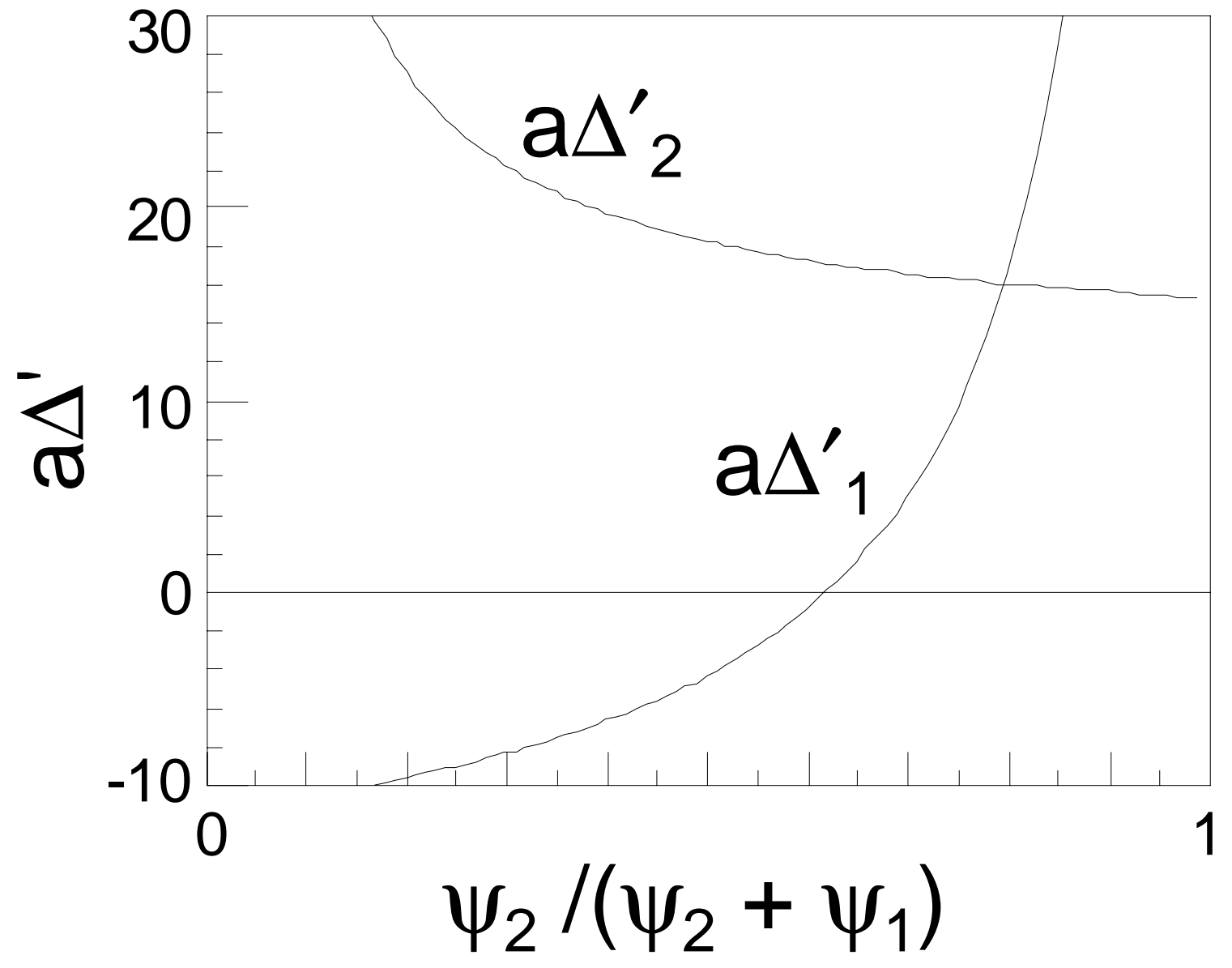




\section{Figure 4}
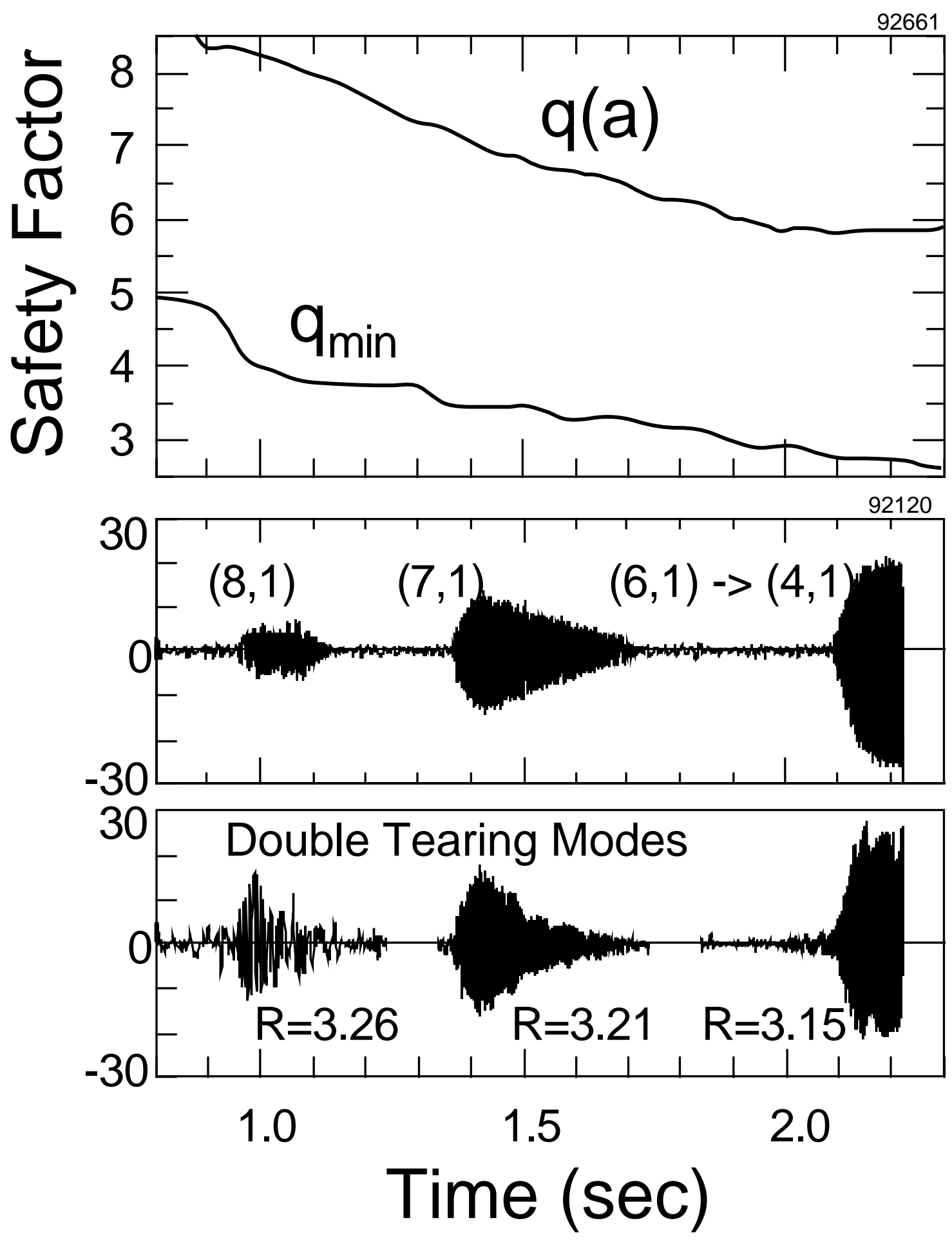
Figure 5

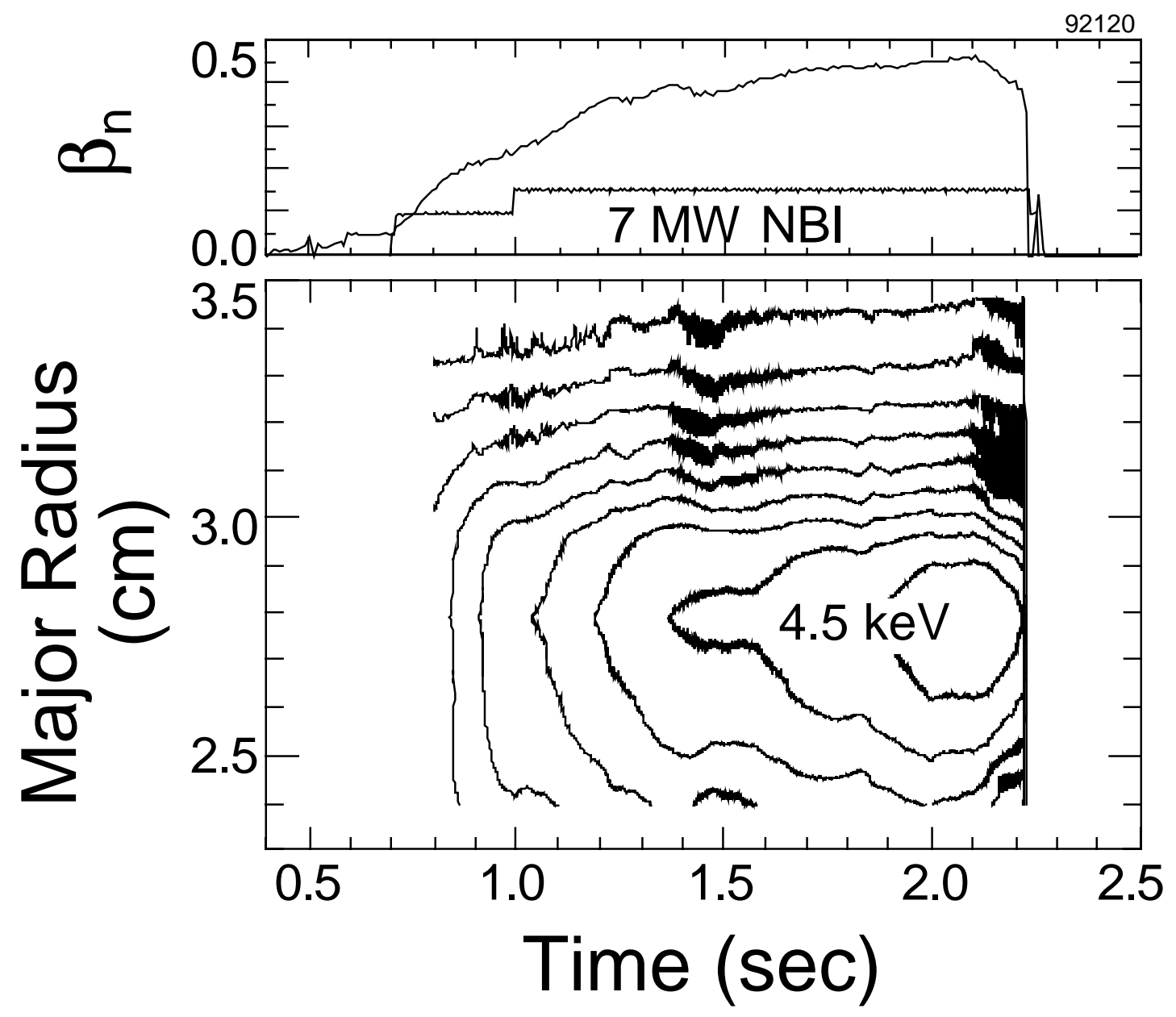


Figure 6a

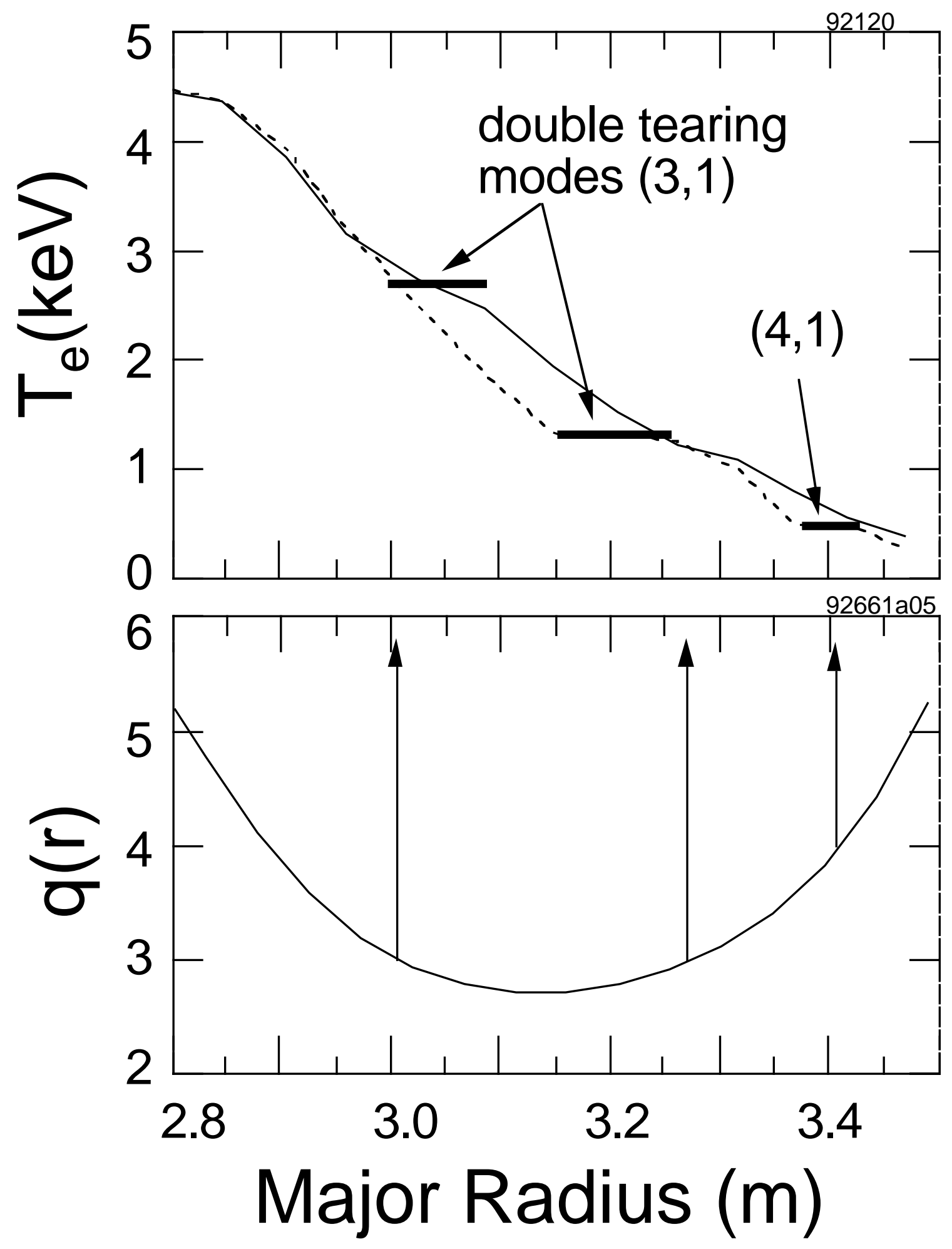


Figure $6 b$

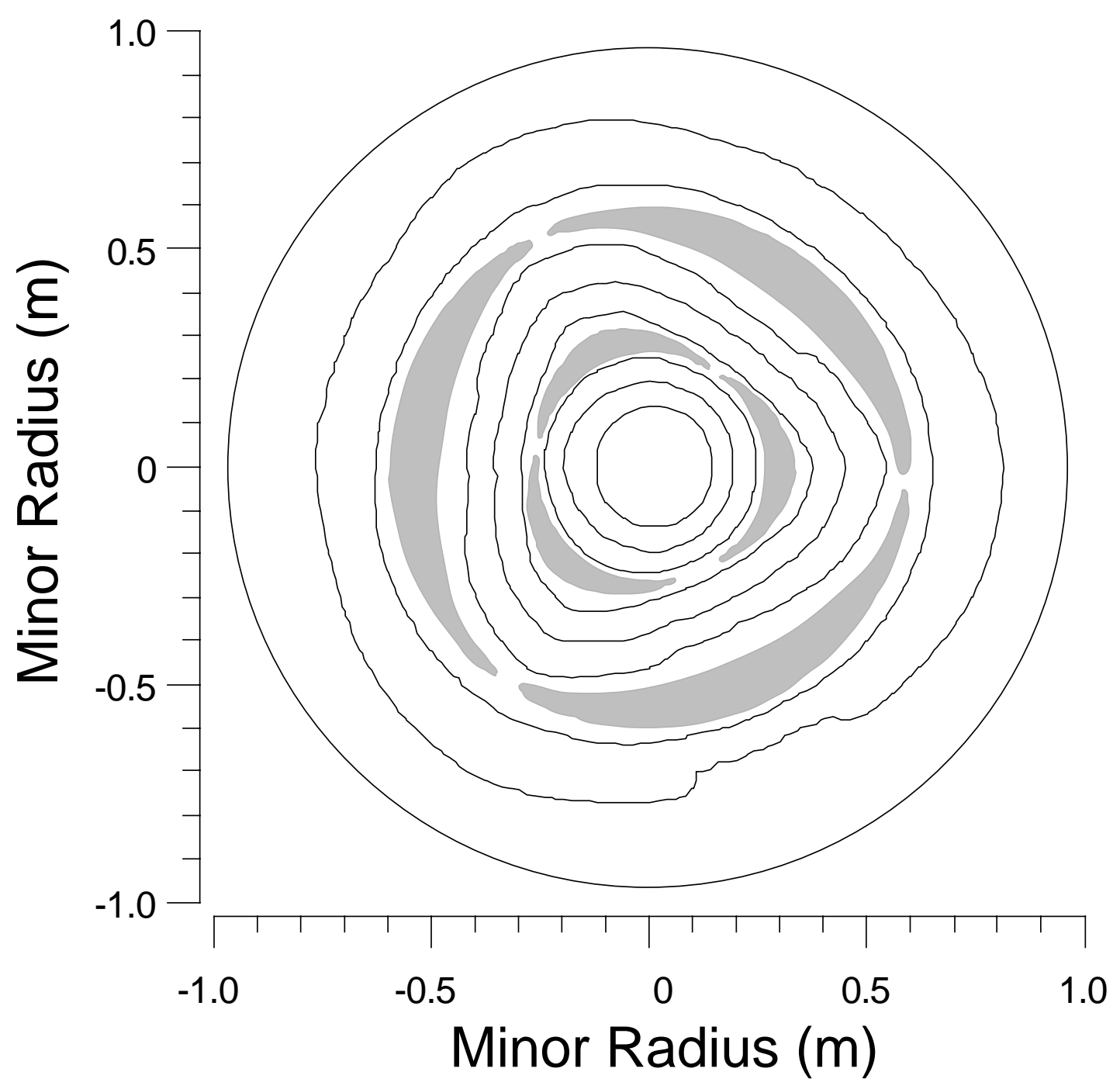


Figure 7a

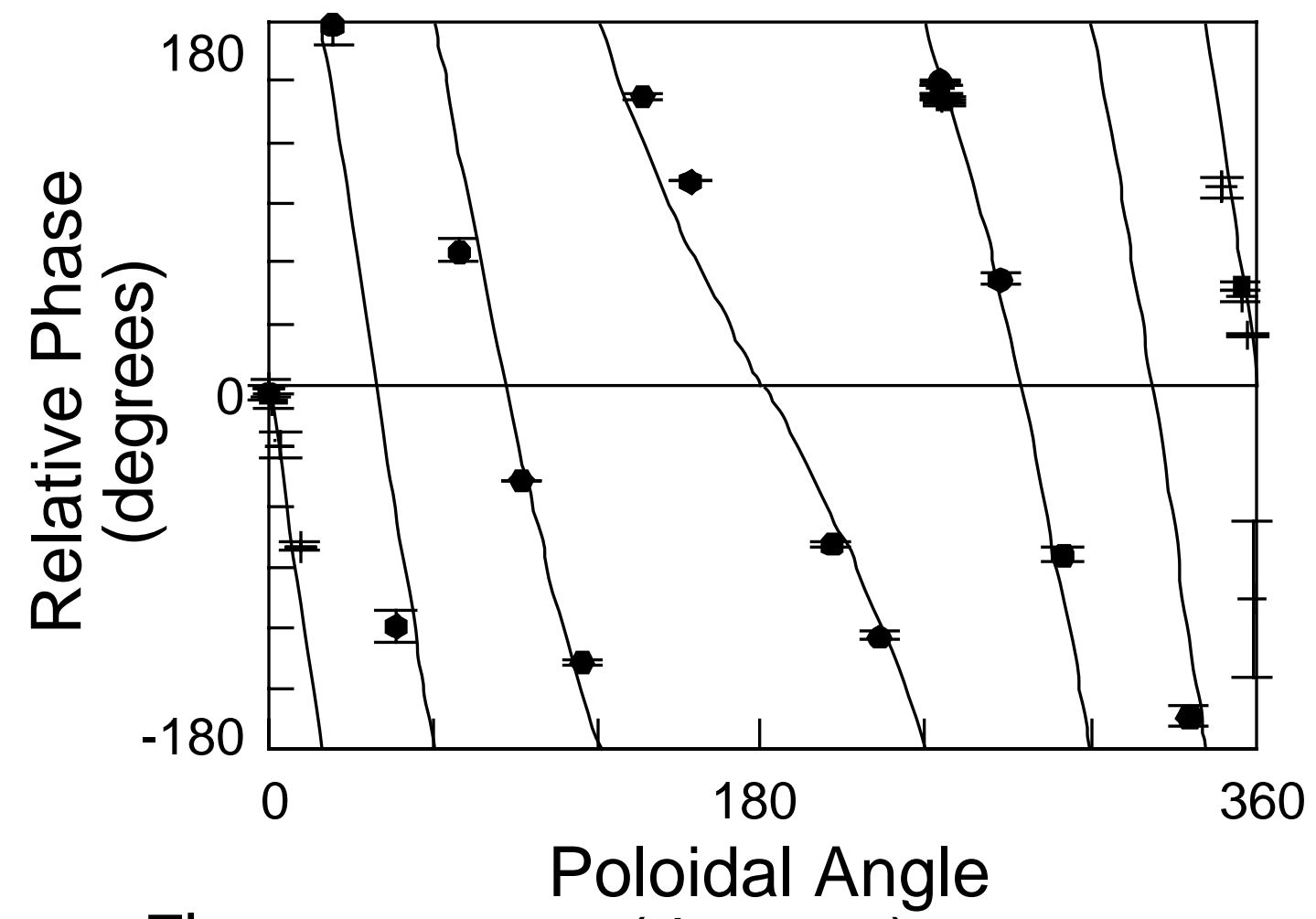

Figure $7 b$

(degrees)

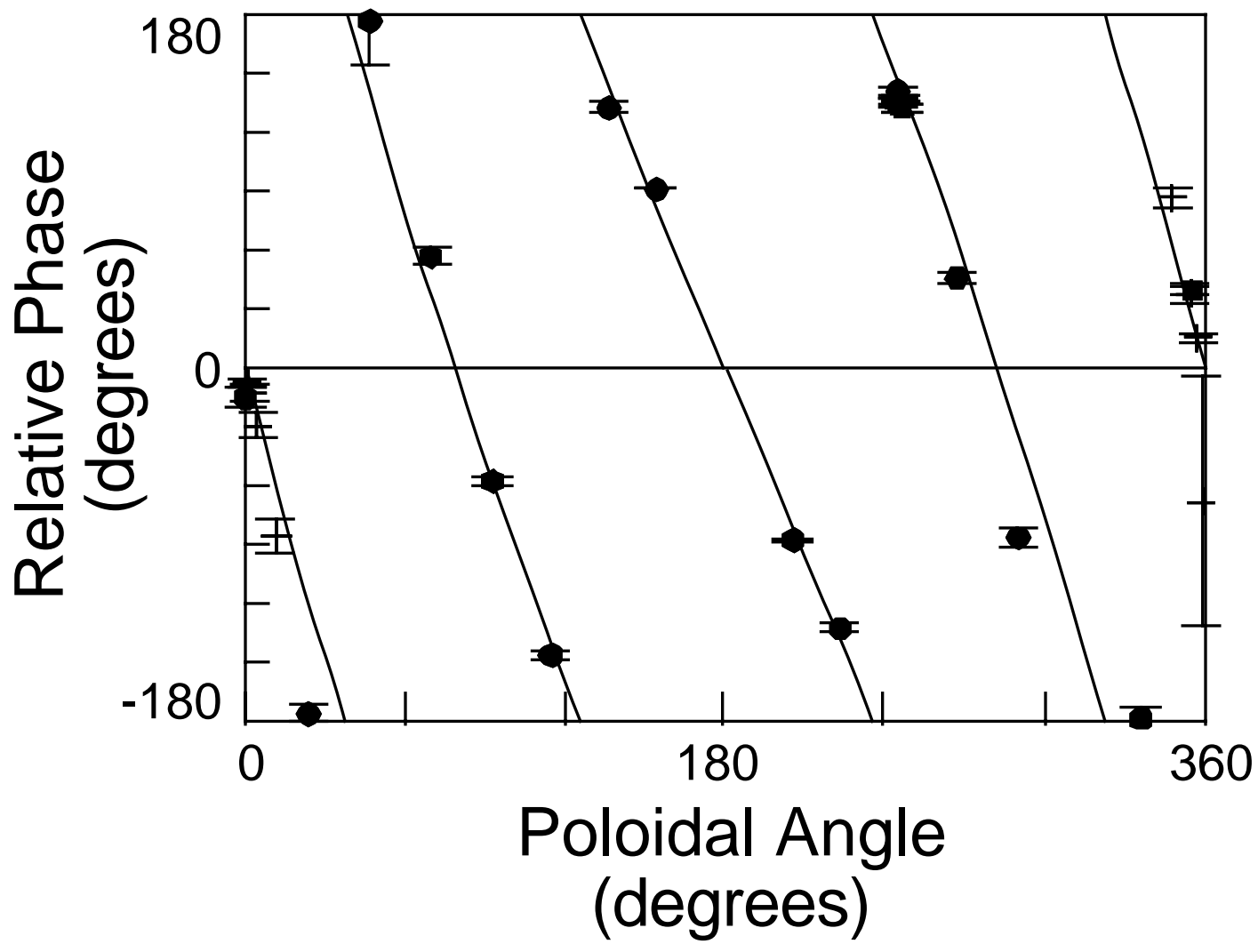


Figure 8
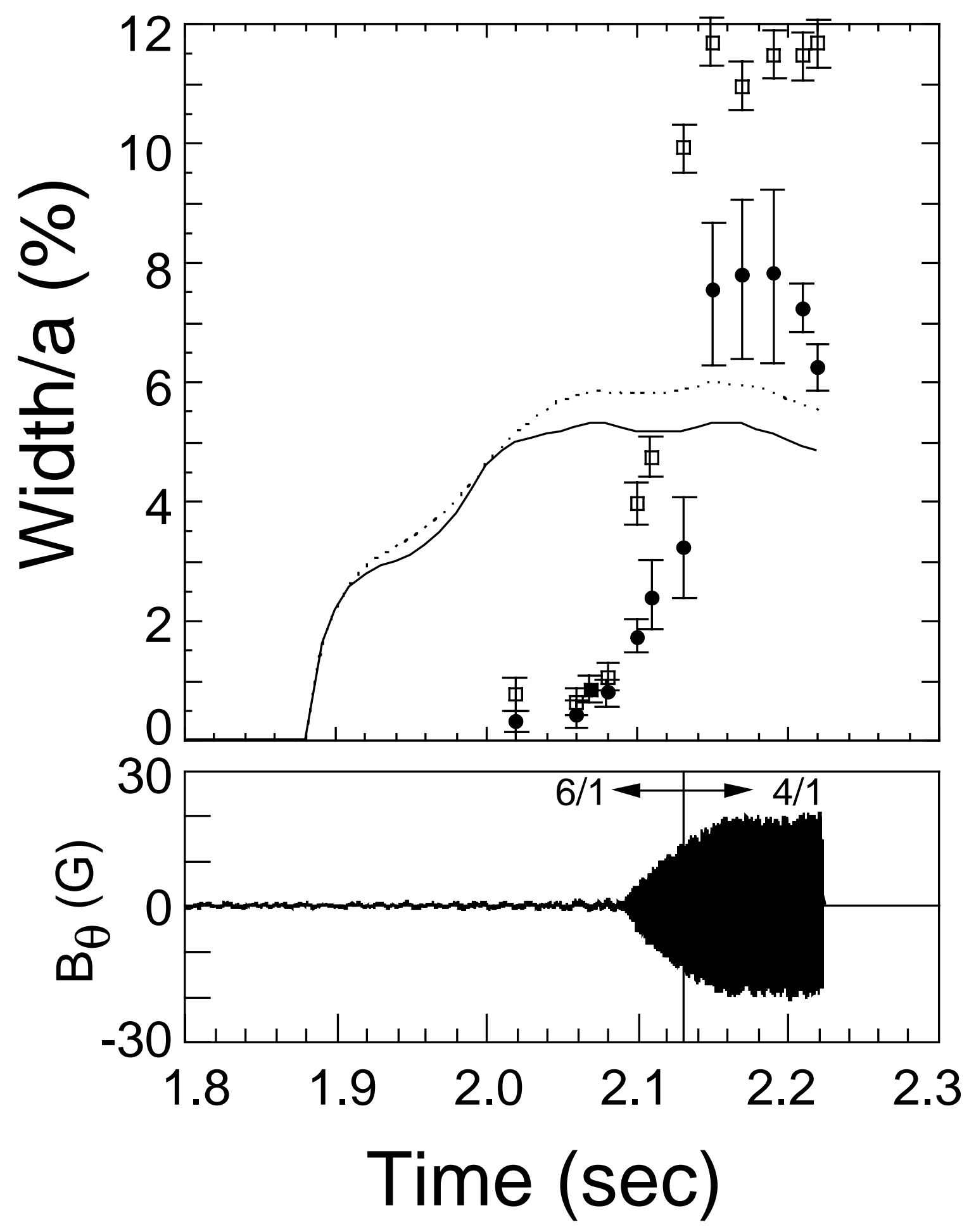
Figure 9

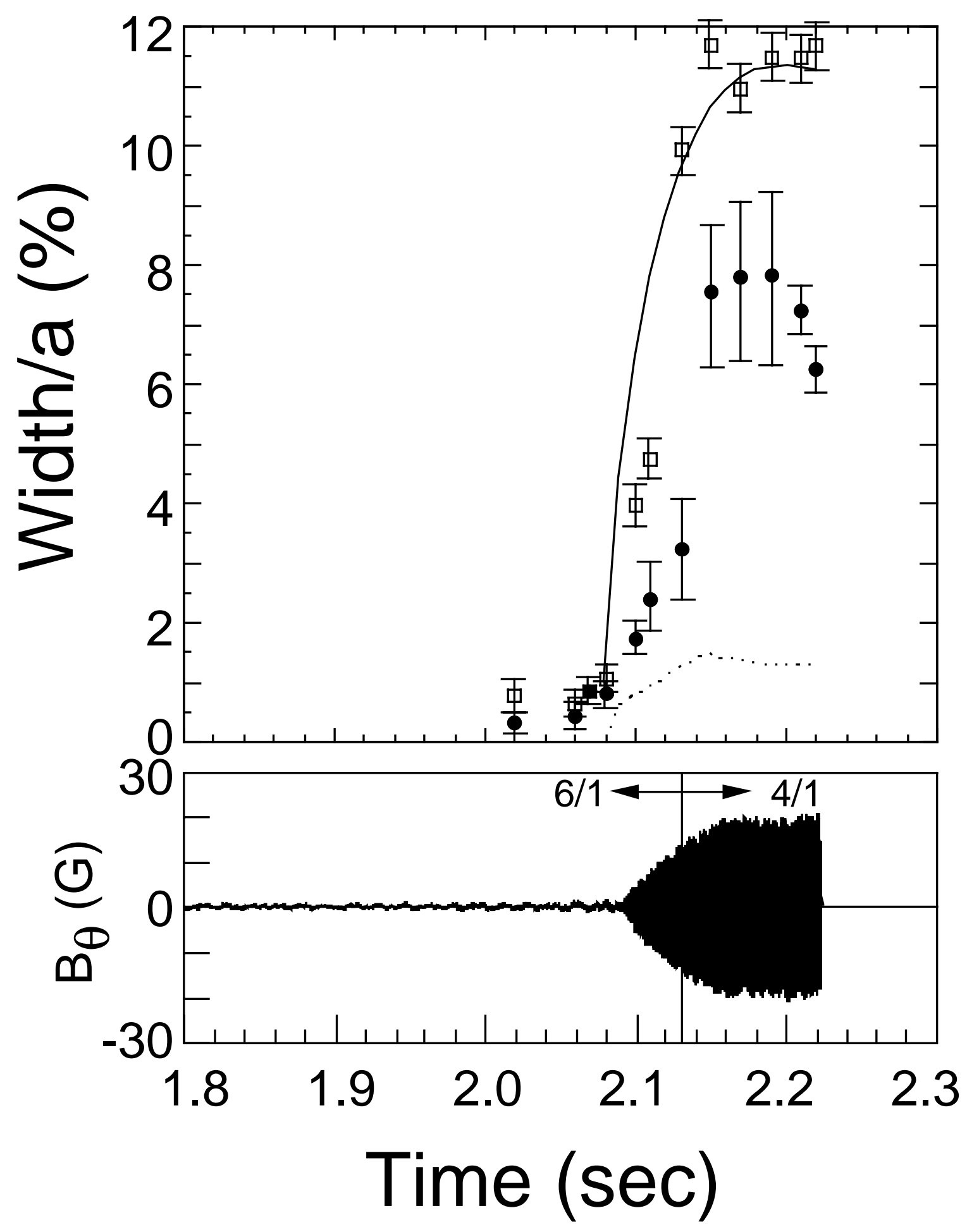


Figure 10

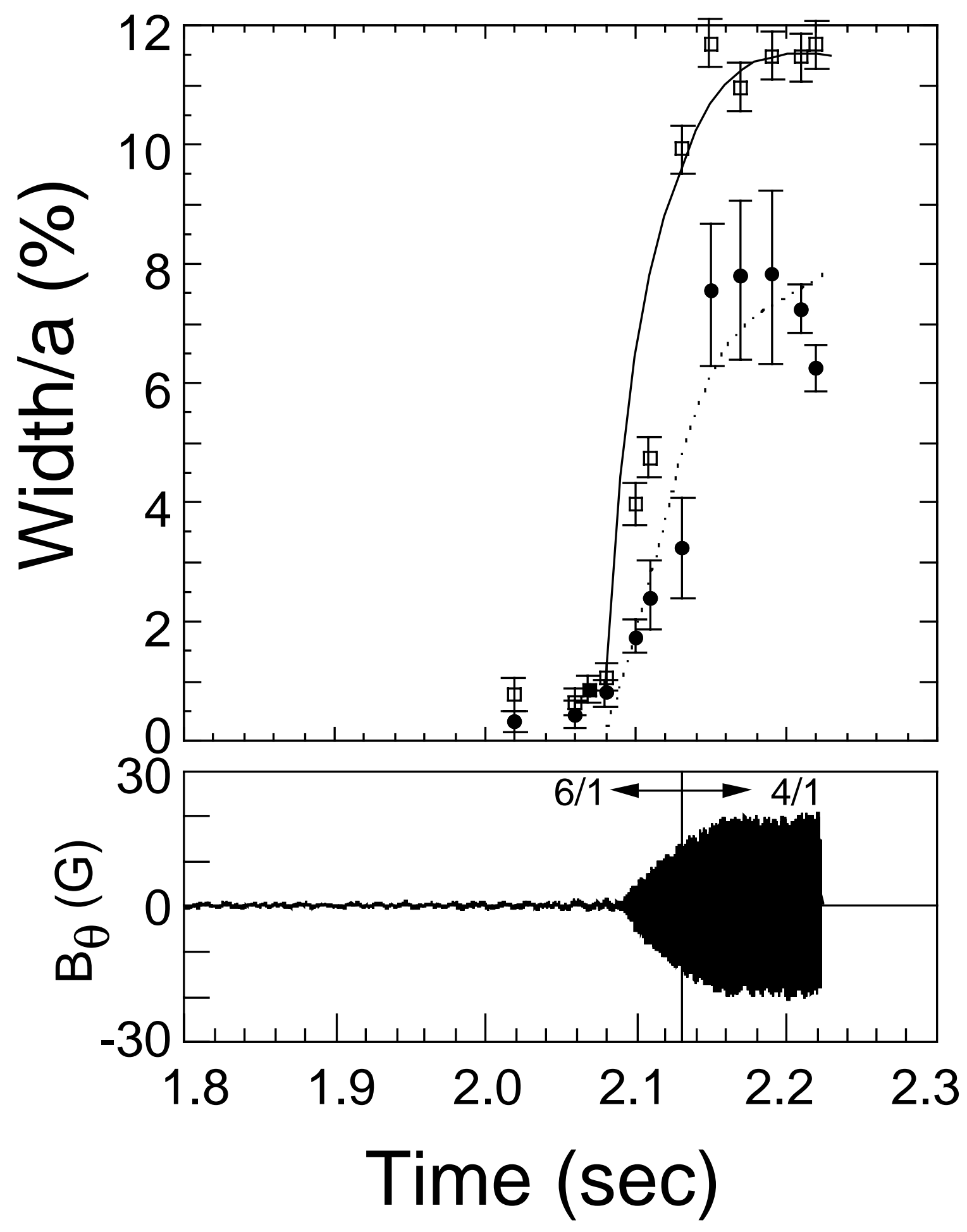

